\title{
Effective Medical Writing: The Write Way to Get Published
}

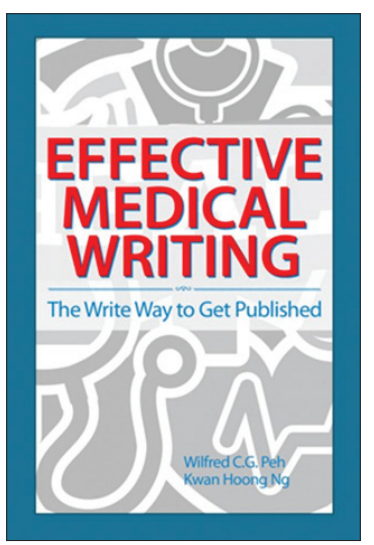

Authors Wilfred CG Peh and Kwan Hoong Ng

Publisher University of Malaya Press, Kuala Lumpur, Malaysia

Published 2016

Pages 206, Paperback

ISBN 9789831008584

Retail price MYR 32 (Malaysian market); USD 27.20 (international market)

This book is equally useful for both the novice researcher looking to successfully publish his or her first work and the experienced researcher who has multiple publications. It guides the novice to explore the motivation to publish as well as the various types of papers that may be submitted. Written by two very experienced editors of medical journals, this book also provides a valuable glimpse into the minds of editors. It can help the novice to focus right from the start by deciding which materials are more likely to be published and worth working on. To the experienced writer of research papers, this book serves as a good platform and teaching base to tutor juniors in effective medical writing. Although getting published does provide certain benefits for the researcher, the ultimate sense of accomplishment comes from seeing oneself as an author of a good publication and being able to contribute to the body of medical knowledge that drives research.

In 31 chapters from 'Why Write?' to 'Publication Ethics and Scientific Misconduct', the authors give focused insight into the requirements of writing various types of publications; to help the busy reader, two or three points at the end of each chapter summarise the topic. This book stands out from the many guidebooks on scientific publication, as it provides an easy read with a clear and concise message. An academic department would certainly find it useful for its clinicians and scientists, and I strongly recommend having a copy in the libraries of clinical departments. Budding researchers should get a personal copy as well.

Effective Medical Writing begins by questioning the motivation to write and ends with a cautionary note on the 'sacredness' of scientific publication. It is important to question and explore our motive to write and publish. As the journey to publication is usually not plain sailing, knowing our motives keeps us focused and persistent in our endeavours. Chapters 2-12 outline the types and structures of different scientific papers with detailed chapter-to-chapter descriptions that guide readers in titling their paper, writing the abstract, introduction, methods and materials, results and discussion, and selecting keywords. This includes four chapters dedicated to statistical results and the presentation of results using tables, graphs, figures, images and diagrams. In these chapters, the discussion centres around the appropriateness of each format and how to optimise its use to present the intended message effectively.

Chapters 13-19 guide the readers through authorship and acknowledgements, references, preparation for submission, and the submission process. The authors even provide a peek into the minds of the editorial staff, editor and reviewers by including some tips for handling returned manuscripts and reading proofs. Having an understanding of the system minimises the pain of article submission and publication. The next nine chapters highlight the different formats to use when writing a case report, technical note, pictorial essay, review article, systematic review, invited commentary, letter to the editor, editorial and book review. The chapter on book reviews forms the general template for this article.

The last two chapters are the two most important chapters in the whole book. A must-read, they caution the researcher about issues pertaining to conflict of interest, copyright, declaration, ethics and misconduct in the scientific world. While most technical information on structure and format can be obtained from other sources, these chapters were written by two very senior editors with rich background experience. They can serve as a beacon of light or boundary lines to keep the researcher within a safe frame. The messages in these pages serve as good reminders when pressure mounts in the journey of an academic and publication becomes a benchmark for contract renewal, promotion and bonuses. I recommend reading these two chapters periodically to keep oneself in check and on course.

In summary, this is a book that provides concise instructions, highlighting important 'dos and don'ts' to young researchers. For the more experienced authors, the contents of the book can be used as an effective frame to teach novices as well as to remind ourselves to stay on track as scientists sharing knowledge for the greater good. The format and language of the book make for light reading. This does not, however, mask or negate its serious message: to be honest and truthful in reporting our research. 